Max-Planck-Institut für demografische Forschung

Max Planck Institute for Demographic Research

Konrad-Zuse-Strasse 1 - D-18057 Rostock - GERMANY

Tel +49 (0) 3812081 - 0; Fax +49 (0) 3812081 - 202;

http://www.demogr.mpg.de

MPIDR WORKING PAPER WP 2009-025

OCTOBER 2009

\title{
Can child care policy encourage employment and fertility? \\ Evidence from a structural model
}

Peter Haan

Katharina Wrohlich (kwrohlich@diw.de)

This working paper has been approved for release by: Michaela Kreyenfeld (kreyenfeld@demogr.mpg.de), Acting Deputy Head of the Laboratory of Economic and Social Demography.

(C) Copyright is held by the authors.

Working papers of the Max Planck Institute for Demographic Research receive only limited review. Views or opinions expressed in working papers are attributable to the authors and do not necessarily reflect those of the Institute. 


\title{
Can child care policy encourage employment and fertility? Evidence from a structural model *
}

\author{
Peter Haan ${ }^{\dagger}$ and Katharina Wrohlich ${ }^{\ddagger}$
}

October 14, 2009

\begin{abstract}
In this paper we develop a structural model of female employment and fertility which accounts for intertemporal feedback effects between the two outcomes. We identify the effect of financial incentives on the employment and fertility decision by exploiting variation in the tax and transfer system which differs by employment state and number of children. To this end we simulate in detail the effects of the tax and transfer system including child care costs. The model provides estimates of structural preferences of women which can be used to study the effect of various policy reforms. In particular, we show that increasing child care subsidies conditional on employment increases labor supply of all women as well as fertility of the childless and highly educated women.
\end{abstract}

Keywords: employment, fertility, financial incentives.

JEL Classification: C23, C25, J22, J64.

${ }^{*}$ The authors would like to thank Josh Goldstein, Michaela Kreyenfeld, Victoria Prowse, Kostas Tatsiramos and seminar participants at Max Planck Institute for Demographic Research for useful comments and suggestions. The usual disclaimer applies.

${ }^{\dagger}$ Max Planck Institute for Demographic Research Rostock and DIW Berlin, phaan@diw.de

${ }^{\ddagger}$ DIW Berlin; kwrohlich@diw.de 


\section{Introduction}

Over the last decades there has been a dramatic decline in the birthrate in most developed countries. At the same time employment rates of women have been increasing. However, in most countries female employment rates, in particular of mothers with young children, are still fairly low. One prominent example of a country with low fertility rates and low mothers' employment rates is Germany. In the year 2006, the total fertility rate in Germany was 1.33 and thus one of the lowest among OECD countries. While the overall female employment rate in Germany $(62 \%)$ is above the OECD average (57\%), the employment rate of mothers with young children is relatively low. Only $36 \%$ of all mothers with children below the age of three years are employed and the employment rate for mothers with the youngest child aged three to five years amounts to $55 \%$ (all numbers OECD (2007)).

Given these demographic challenges, policy makers in all countries have introduced fiscal instruments intending to encourage female employment and fertility. Examples are the Earned Income Tax Credit (EITC) in the US, the Working Tax Credit (WTC) in the UK or the French Family Tax Splitting. Moreover, most countries directly transfer money to families with children through universal chid benefits or through subsidized child care facilities and provide parental leave schemes.

Previous empirical literature provides mixed evidence about the success of these policy instruments in fostering female employment or fertility 1$]$ Household based in-work credits such as the EITC or the WTC induce positive and significant participation effects for single mothers, however they tend to reduce the labor supply of secondary earners (Blank, 2002; Blundell, 2000; Hotz and Scholz, 2003). Since eligibility of these programmes is conditional on having children, both the EITC and the WTC might positively affect fertility. Brewer et al. (2008) provide evidence for significant fertility effects of in-work credits for the UK, and for the US, Baughman and Dickert-Conlin (2003) show that the EITC had an effect on fertility. Amongst others, Lalive and Zweimueller (2005) find that the duration of parental leave has a positive and sizable effect on fertility and a negative impact on employment. While universal child benefits which are unconditional on the employment state tend to have positive effects on fertility (e.g. Milligan (2005)), the causal effect of subsidized child care facilities on the number of children born is less clear. For the US, Blau and Robins (1989) find evidence that child care costs negatively affect the fertility decision. For Germany, it has been shown by Hank et al. (2004) that the availability of full-time subsidized child care positively affects fertility. Finally, in a recent study on Spain, Azmat and Gonzalez (2009) show that the combined introduction of a tax credit for working mothers and of child deductions for all household had a positive effect on both female employment and fertility. However, the authors argue that the overall child deductions significantly reduced the positive employment effects.

The aim of this paper is to provide further empirical evidence how child related transfers affect fertility and the female employment behavior. In particular we evaluate the employment and fertility effects of subsidized child care. Since only working women benefit from subsidized

\footnotetext{
${ }^{1}$ For a detailed survey, see Gauthier (2007).
} 
child care, this particular reform might tackle the two demographic challenges, i.e. low fertility and low female employment rates at the same time. In contrast to most of the previous literature which identifies the effects of financial incentives directly from policy reforms using standard evaluation techniques, e.g. Lalive and Zweimueller (2005), we develop an intertemporal structural model which allows us to estimate the behavioral responses of child care reforms. Therefore, our paper has two main contributions.

First, we propose an identification strategy of an intertemporal structural model of female employment and fertility. As in Laroque and Salanie (2008), identification relies on variation of financial incentives by working hours, number of children and gross household income. In contrast to Laroque and Salanie (2008) however, we allow for intertemporal feedback effects between employment and fertility similar to e.g. Carrasco (2001). We model the employment and fertility decision jointly to control for simultaneity of both processes and account for intertemporal non-separable preferences by estimating a dynamic panel data model with random effects and an appropriate treatment of the initial conditions problem. Finally, we follow Laroque and Salanie (2008) by modelling in great detail the variation in financial incentives, which in our case not only result from the tax-transfer system but also from child care institutions. Estimation is based on a sample of married and cohabiting women for the period 2000 - 2007 using panel data from the German Socio Economic Panel (SOEP).

The second contribution of the paper is the evaluation of the employment and fertility effects induced by a child care reform. Such a reform induces financial incentives only for women in employment with newborn children and is therefore most promising to tackle the demographic challenges of a society with low fertility rates and low female employment. Thus, the key question we want to answer in this analysis is if there exists empirical evidence for this double positive effect of the child care reform. In order to get a better understanding of the size and importance of the effects we compare the behavioral effects of this child care reform with the effects induced by universal child benefits. Both reforms are designed such that before behavioral adjustment they have the same fiscal costs.

The empirical results show that child care subsidies targeted at working mothers induce sizable employment effects yet overall there are no positive significant fertility effects. However, we find that for two subgroups, namely highly educated women, and women without other children, subsidized child care would increase fertility in similar magnitude as a universal child benefit.

The rest of the paper is organized as follows. In the next section we develop the model and discuss in detail the empirical strategy and identification. Then we present the data, descriptive evidence and the estimation results. Based on the estimation we evaluate the behavioral effects of the child care reform. The final section concludes.

\section{Overview of the model}

There exists a large empirical literature on female employment behavior and the fertility decision. Models range from reduced form static specifications which treat the employment and fertility 
decision separately to dynamic structural life cycle models where women maximize life cycle utility and jointly determine their optimal behavior, e.g. Francesconi (2002). Keane and Wolpin (2002) show that a first order Markov model serves as a good approximation of the predicted optimal fertility and employment behavior over the life-cycle. Therefore numerous recent studies have adopted a flexible specification of a first order Markov model to estimate the life-cycle behavior with respect to employment and fertility. Recent examples include Carrasco (2001), Del Boca and Sauer (2006) or Michaud and Tatsiramos (2008) 2 Michaud and Tatsiramos (2008) stress the importance to allow for the endogeneity of fertility when approximating life-cycle employment of women, as the strict exogeneity assumption would rule out any intertemporal feedback effects between employment and fertility. To account for this endogeneity Carrasco (2001) and Michaud and Tatsiramos (2008) analyze female employment and fertility jointly in a dynamic bivariate-probit panel model and for identification they use the sex composition of siblings as an exclusion restriction.

In our analysis we closely follow the recent literature and approximate the life-cycle behavior of women in a first order Markov model. However in contrast to Carrasco (2001) and Michaud and Tatsiramos (2008) we use a different approach to account for the simultaneity between fertility and employment. In particular, we follow the idea of Laroque and Salanie (2004) and Laroque and Salanie (2008) and use an identification strategy that relies on the fact that employment and fertility behavior induces variation in the net incomes through the tax and transfer system and through child care institutions among comparable households. The variation can be exploited to estimate the sensitivity of fertility and employment with respect to financial incentives. In contrast to Laroque and Salanie (2008) we apply this methodology not to a static model of female behavior but place it in the intertemporal setting discussed above. In the following section we will in detail discuss how the German tax and transfer system induces variation by fertility and employment status and we will provide evidence that this variation is of important size. In addition to income taxation and direct transfers the government introduces financial incentives through subsidized child care. We will show that the subsidies strongly vary by region which introduces further variation. Finally, we can exploit the time dimension of the panel data. Over the observed time span several reforms of the tax and transfer system and changes in the availability of subsidized child care have altered the financial incentives for households differently by region.

\subsection{Empirical model}

In this analysis, we focus only on married and non-married cohabiting couples, indexed $i \in I$. In each period a household derives utility from net household income $Y_{i t}$, leisure time $L_{i t}$ and from a newborn child $F_{i t}$. Leisure time is defined as non-working time. Hence, we don't distinguish between leisure time spent with and without children. Further, as common in this literature we do not account for savings and thus we assume that net household income equals consumption.

We simplify the utility maximization of the household and do not consider collective bar-

\footnotetext{
${ }^{2}$ Hyslop (1999) derives a dynamic employment model which is consistent with life-cycle optimization
} 
gaining between the spouses. Instead, we assume that the wife optimally decides about her employment and fertility behavior and maximizes the household utility conditional on her husband's behavior 3 We approximate the employment behavior with $E$ discrete employment states and assume that the women can choose between non-employment, marginal employment and regular employment. Moreover, the household decides about fertility $F$ which is a binary choice variable. To model employment and fertility jointly we allow for all working and fertility combinations which in total results in a choice set of $E \times F=J$ combinations. The net household income $Y_{i t}$, which is calculated using a microsimulation model, varies for all $\mathrm{J}$ combinations, leisure time $L_{i t}$ varies by the E different employment states and the indicator for a newborn by fertility state $F_{i t}$.

\section{Timing of events}

When analyzing the female employment behavior and the fertility decision jointly it is necessary to define the timing of both events. It is very unlikely that the observed employment decision at the birth date of the newborn or even in the first month after birth reflects the optimal decision of the mother in the first period, i.e. in the first year. In Germany, maternity protection laws strictly forbid employment 6 weeks before and 8 weeks after giving birth. Thus, if only yearly observations about the employment behavior is available it is problematic to assume that both events take place in the same period $t$.

In this study we use monthly employment information and combine this with the birth date of a child (i.e. month of birth) to construct an exact timing of events for each woman. Female employment behavior depends heavily on the age of the newborn in the first year. In our data we basically observe no employed mothers with a newborn younger 6 months, and the employment rates hardly increase until the newborn reaches the first birthday. Thus, it seems that the relevant decision of the mother to take up employment takes place only a year after she gave birth. Therefore, in the following we assume that the employment decision at time $t$ is observed when the age of the newborn is 12 months. For consistency we drop households with newborns younger than 12 months.

\section{Empirical specification}

The model proceeds as follows. In each period $t$ the wife maximizes the utility of the household conditional on the behavior of her partner by jointly choosing her employment and fertility state. We allow for heterogeneity between households and model the preferences depending on observable and unobservable characteristics. We condition the behavior of the women on standard demographic characteristics $X_{i t}$ such as age, education, marital status or nationality as well as on the number of other children younger than 18 years living already in the household. Moreover we model preferences as a function of the previous employment state $E_{i t-1}$ and fertility

\footnotetext{
${ }^{3}$ At first glance this often applied simplification might seem restrictive. However, empirical evidence suggests that cross elasticities between spouses are either not significant or of little importance (Steiner and Wrohlich, 2004) and this provides justification for this assumption.

${ }^{4}$ In the SOEP only since 2001 information is available to distinguish between mandatory maternity leave and voluntarily chosen parental leave.
} 
in the last period $F_{i t-1}$. The conditioning on the lagged employment and fertility status makes our model intertemporal in line with a first order Markov process. Further, we account for unobservable effects which might influence the optimal choice of the women. We distinguish between individual specific random effects $a_{i}$ which are time constant and error terms $\epsilon_{i j t}$ which vary over time, individuals and choice combinations.

We follow the literature on discrete choice models (McFadden, 1974) and assume the error terms $\epsilon_{i j t}$ to follow an i.i.d. extreme value distribution. Given this assumption the probability that household $i$ chooses alternative $j$ at period $t$ can be expressed as:

$$
P r_{i j t}=\frac{\exp U\left(Y_{i j t}, L_{i j t}, F_{i j t} \mid X_{i t}, E_{i t-1}, F_{i t-1}, a_{i}\right)}{\sum_{r=1}^{J} \exp U\left(Y_{i r t}, L_{i r t}, F_{i r t} \mid X_{i t}, E_{i t-1}, F_{i t-1}, a_{i}\right)} .
$$

In general intertemporal models based on panel data suffer from the problem of initial conditions. This problem arises as the employment status and the fertility of a women observed in the initial observation $t=0$ cannot be assumed to be random. In fact it is likely that non-random unobservable effects are correlated with the status in the initial state. To account for the initial condition problem we follow Wooldridge (2005) and model the distribution of the individual specific random effects $a_{i}$ conditional on the initial observation. This method is operationalized by allowing the mean of the individual specific unobserved effect to depend on the first observation of the female's employment status and the number of children younger 18 years in the initial period. The remaining stochastic element of the individual random effect, denoted with $c_{i}$, will be nonparametrically specified as discussed below 5

We parameterize the above defined utility function with a log specification of the net household income, denoted by $y_{j t}$, linear and quadratic terms for the female leisure time, and with a discrete indicator for fertility. Moreover, we allow for multiple interaction of the three factors. This specification guarantees that utility is concave in income but it allows the shape of the utility function to be completely flexible with respect to the leisure and fertility term. Suppressing the indicator for the household, the utility level at alternative $\mathrm{j}$ and time $\mathrm{t}$ has the following form:

$$
U_{j t}=\beta_{y} y_{j t}+\beta_{l y} y_{j t} L_{j t}+\beta_{l} L_{j t}+\beta_{l l} L_{j t}^{2}+\beta_{f} F_{j t}+\beta_{f l} F_{j t} L_{j t}+\beta_{f y} F_{j t} y_{j t} .
$$

Preferences for income vary by the age of both partners, and the total number of children living in the household $X_{y t}$. Preferences for leisure time are affected by several demographic characteristics denoted with $X_{l t}$ including age, education, marital state, nationality and region. Moreover the lagged employment and fertility state and the variables describing the initial state are included in matrix $X_{l t}$. Similarly, preferences for fertility vary by observables $X_{f t}$ including the behavior in the lagged period and in the initial observation.

\footnotetext{
${ }^{5}$ Akay (2009) performs several Mote Carlo simulation to study the performance of the Wooldridge method. He finds that in moderately long panels with more than 5 periods the methods performs well relative to other procedures to account for the non-random selection.
} 


$$
\begin{aligned}
\beta_{y} & =\alpha_{y 0}+\alpha_{y 1} X_{y t}+c_{y} \\
\beta_{l} & =\alpha_{l 0}+\alpha_{l 1} X_{l t}+c_{l} \\
\beta_{f} & =\alpha_{f 0}+\alpha_{f 1} X_{f t}+c_{f}
\end{aligned}
$$

As mentioned above, vector $c_{i}$ captures the remaining stochastic element of the individual specific random effect $a_{i}$. We specify $c_{i}$ nonparametrically as random coefficients of $\beta_{y} \beta_{l} \beta_{f}$ following Heckman and Singer (1984) with K points of support and allow the random coefficients to correlated. More precisely the random coefficients are described by three points of support (mass points) for income $\left(c_{1}^{y}, c_{2}^{y}, c_{3}^{y}\right)$, leisure $\left(c_{1}^{l}, c_{2}^{l}, c_{3}^{l}\right)$ and fertility $\left(c_{1}^{f}, c_{2}^{f}, c_{3}^{f}\right)$ which load on one probability vector. This specification is flexible enough to freely estimate the correlation of the unobservables between the three preference terms.

Mass points and the transformed probabilities $\pi$ are jointly estimated with the parameters by maximum likelihood $\sqrt[6]{6}$ The likelihood to be maximized is then:

$$
L=\prod_{i=1}^{n} \sum_{k=1}^{3} \pi_{k}\left(a^{k}\right) \prod_{t=1}^{T} \prod_{j=1}^{J} \operatorname{Pr}(J=j)^{d_{i t j}},
$$

where $d_{i t j}=1$ if $\mathrm{j}$ is the chosen alternative and 0 otherwise.

\subsection{Identification}

As mentioned above, for the identification of the joint decision about employment and fertility we follow Laroque and Salanie (2008) and exploit the variation in net income by number of children and employment states through the tax-transfer system including child care institutions. The required variation results mainly from joint taxation of spouses with full income splitting, the design of out-of work transfers, child rearing benefits which are means-tested, child benefits which are not means-tested, a tax allowance for children, and subsidized child care facilities. In the following we will briefly discuss the institutional features and provide empirical evidence about the magnitude of the variation we use for our identification strategy.

\section{Joint income taxation}

In Germany, married spouses can file taxes jointly and make use of full income splitting, which leads to high marginal tax rates and low work incentives for secondary earners. This is particularly true for employment above "marginal employment" defined as employment with a salary of less than 400 Euro per month, since only income above this threshold is due to social security contributions and income tax.

\section{Child-rearing benefit}

A second part of the tax-transfer system that is essential for our application is the child-rearing benefit ("Erziehungsgeld"). This is a means-tested transfer for families with children in the first

\footnotetext{
${ }^{6}$ Probabilities are transformed to guarantee positive probabilities that add up to unity.
} 
two years after birth. It is granted if at least one parent works less than 30 hours per week. In addition, there is an income thresholds up to which the benefit is granted (16,500 Euro per year for a couple household); above this threshold, the benefit is withdrawn at a rate of $63 \% .7$ Thus, the child-rearing benefit depends on both, absolute income of the household if the mother does not work and on her working hours.

\section{Child benefit and child tax allowance}

Another important benefit for families in Germany is the universal child benefit ("Kindergeld") that is granted for each child until the age of 18 years 8 For the first and second child, it amounted to 130 Euro per month in 1999 and was raised to 138 Euro in 2000 and to 154 Euro in 2002. For the third child it amounts to 154 Euro and for the fourth and every subsequent child to 179 Euro, respectively, during the whole observation period. In addition to variation across birth order of the child and the time period, additional variation comes from the fact that this child benefit is accounted against the child tax allowance ("Kinderfreibetrag"). The child tax allowance can be deducted from taxable income and amounted to 3,534 Euro per year in 1999 and was raised to 5,080 in 2001 and to 5,808 in 2002. The child tax allowance leads to a higher return than the child benefit for tax filers with a pre-tax income of 60,000 Euro or more. Only one of the two, benefit or tax-allowances, is granted at the same time. The tax authorities calculates which is more beneficial for every tax filer.

\section{Out-of work transfers}

In addition to these family- or child-related benefits, there exist the general means-tested outof work benefits ("Arbeitslosengeld II") and housing benefits that also depend on the number of children 9 Moreover in 2005, the government introduced an in-work tax credit for families ("Kinderzuschlag") that is granted to parents who have earnings that cover their own means but not those of their children. This benefit amounts to a maximum of 140 Euro per month, however, only within very small income brackets.

\section{Empirical evidence of income variation by gross earnings}

In Figure 1 we summarize how the mentioned features of the tax and transfer system affect the net household income by gross earnings, which strongly depend on female employment, and by the presence of a newborn. In particular, the graph shows the difference in the available net household income for a household with and without a newborn. Figure 1 only reflects the effects of the tax and transfer system without subsidies for child care costs which will be discussed below.

\footnotetext{
${ }^{7}$ In 2007, the "Erziehungsgeld" has been replaced by a new parental leave benefit ("Elterngeld") that is not means-tested but rather depends positively on pre-birth earnings and is granted for one year. Since this reform was established after the end of our observation period, this is not relevant for our analysis. For more details on the old and the new parental leave benefit, see Spiess and Wrohlich (2008).

${ }^{8}$ If a child is in education, the benefit can be drawn up to the age of 25 .

${ }^{9}$ In addition to the means tested out-of work benefits unemployed might be eligible for temporary unemployment benefits. Since in this study we analyze the employment behavior on a yearly basis we abstract from the temporary transfers.
} 


\section{[Figure 1 : about here]}

At very low gross earnings, the additional net income in case of a newborn child is very high, amounting to about 600 Euro per month. This is due to the fact that (i) out-of work transfers are higher for households with a child and that (ii) the child-rearing benefit is granted in addition to social assistance 10 At about 20,000 Euro of gross annual earnings, the gain in net income is even higher due to the "Kinderzuschlag", however this benefit is withdrawn at a relatively high rate. Above that threshold, also the child-rearing benefit is withdrawn, and so the income difference markedly drops to around 160 Euro per month. Above 40,000 Euro gross income per year, there is only little variation due to the tax system. Around 41,000 Euro a non-linearity is induced by the solidarity surcharge that is lower for families with children. Above 61,000 Euro, the child tax allowance yields higher returns than the child benefit, therefore the income gain rises linearly from this point on.

\section{Child care institutions}

Variation in net income, or more specific, in disposable income, however does not only result from the non-linearities in the tax-transfer system, but also from regional differences in child care institutions. For children up to three years, availability of public child care is relatively low, in particular in West Germany, although availability has been increasing in recent years. In 2002 , there were public child care slots available only for $3 \%$ of all children in this age group in West Germany; in 2006, this number has increased to 8\% (Wrohlich (2007)). East Germany traditionally has a relatively high availability, with an average of 40 slots per 100 children in this age group (in 2006). However, empirical studies (e.g. Wrohlich (2008)) have shown that in both parts of the country, there is considerable excess demand for subsidized child care. Fees for the subsidized slots are relatively low, amounting to 81 Euro for a part-time slot and 114 Euro for a full-time slot (on average). On the other hand, privately organized child care comes at considerably higher cost, around 5-6 Euro per hour at least. Thus, for families who do not have access to a subsidized child care slot, child care costs are relatively high. As suggested in Wrohlich (2006) and Haan and Wrohlich (2009), we use a measure that takes rationing explicitly into account. Since we do not know if a family we observe in the data is rationed with respect to child care, we assume that parents face "expected" costs of child care that consist of fees for a subsidized slot on the one hand and costs for private child care on the other hand. The two parts are weighted by the local availability of child care centers for the age group of children up to three years ${ }^{11}$ The measure of child care costs that we use in our framework thus increases with the amount of parents' fees to subsidized slots (that mainly depend on region and household income) and decreases with the availability of child care facilities (depends on region).

\section{[Table 1: about here]}

While the fees for subsidized child care remained fairly constant over the observation period, there has been an increase in availability of child care slots, at least in the period from 2002

\footnotetext{
${ }^{10} \mathrm{We}$ assume that this household is only eligible for the means-tested minimum income when out of work.

${ }^{11}$ More details of the calculation of this measure of child care costs are provided in the Appendix.
} 
to 2006. Thus, "expected" costs of child care have been slightly declining. More important, however, is the regional variation. We have information on availability rates of all 440 counties in Germany. Generally, East Germany has higher availability rates than West German states. In both parts of the country, availability is higher in urban than in rural areas. Table 1 shows how child care costs vary across region and population density (all values refer to 2006).

\section{Empirical evidence of income variation by female employment}

Obviously, incentives created by the tax-transfer system and by child care institutions, not only vary by gross household income, but mostly by the employment status of the mother. This is best summarized in budget lines for stylized households (Figure 2) that shows net household income as a function of working hours of the mother. In this stylized household, the father is working full-time and earns the median of the male wage distribution (16 Euro per hour), while the mother varies working hours from 0 to 40 , earning the median of the female wage distribution (12.4 Euro per hour). The black line shows net household income of this couple in case they do not have any children. Except for the kink at around 8 hours per week, where income taxation under the joint tax system sets in, the line runs fairly linear. This is also true for the case in which this family has a newborn child as shown in the dark grey line above, running almost parallel to the black one. This household is not eligible for out-of work transfers or the child-rearing benefit as these social transfers are withdrawn at lower income thresholds. For this household, the only difference comes from the child benefit of 154 Euro.

\section{[Figure 2 : about here]}

The picture changes, however, once we deduct child care costs in case that the mother is working. The disposable income of the family with child care costs is shown in the light grey line. Except for very low working hours of the mother, disposable household income is lower than for the same family without a newborn child. This highlights the strong disincentives for mothers' employment due to high child care costs. While in the case of non-employment, a newborn child increases disposable household income, this is not the case if the mother is working more than a few hours per week. Moreover, since we assume that child care costs increase with working hours of the mother, she can hardly increase the total household income by working longer hours.

\section{Data and descriptive evidence}

\subsection{Data and central variables}

This study draws on data from the SOEP which is an annual representative sample of over 11,000 households living in Germany which contains information about socio-economic variables at the individual and household levels 12 We construct an unbalanced panel of married and cohabiting households with consecutive observations in at least two years between 2000 - 2007 inclusive which yields retrospective information for the fiscal years 2000 - 2006. We exclude households

\footnotetext{
${ }^{12}$ For a detailed description of the data set, see Haisken De-New and Frick (2005).
} 
with primary earnings of the female spouse from self-employment as well as those households where the woman is in full-time education. Further, we only consider households with a female spouse older than 22 and younger than 45 . The upper age limit is defined by the maximum age of fertility. Since we restrict our sample to married or cohabiting couples we observe only very few households with women younger than 25 which full-fill our selection criteria. Therefore, we decided to restrict the sample at the bottom of the age distribution in order to guarantee robust results. These exclusions yield a sample with 10845 person year observations corresponding to 2714 different households.

\section{Employment behavior}

The SOEP includes detailed information about an individual's monthly employment state in the year prior to the interview date. This allows us to precisely identify the working behavior of a mother at a defined period after giving birth. As mentioned above we consider the employment behavior 12 months after birth. The data allow us to distinguish three discrete employment states, non-employment, marginal employment and regular employment. More precisely, we define marginal employment as working less than 12 hours per week, and regular employment working above this threshold. The observed group specific median working hours define the employment in the two working categories, namely 5 hours and 30 hours per week. This classification allows us to distinguish employment which is exempted from social security contributions from regular employment. The latter group however includes both part time and full time working women 13 The three employment states allow us to study the working behavior both on the intensive (working hours) and the extensive margin (participation). As discussed above the fiscal treatment and the financial incentives strongly differ between marginal or part-time employment and full-time employment. Therefore, this distinction is quite important.

\section{Fertility}

The observed birth date of a child defines fertility of the mother. In the sample period we observe 884 newborn children which we can link to socio-economic variables of their parents and the employment status of the mother.

\section{Net household income}

Our identification strategy relies on the net household income which varies by employment and fertility state. The net household income is computed with the microsimulation model STSM (Steiner et al., 2008). Based on variables drawn from the SOEP, gross earnings, the taxable income, the amount of income taxes and all important transfers can be derived at the household level. This information together with the imputed household specific child care costs is sufficient to describe the work incentives for each woman for all $\mathrm{J}$ employment and fertility states. Gross household income consists of the observed earnings of the husbands, the alternative specific

\footnotetext{
${ }^{13}$ Before 2004, it is not possible to distinguish between part-time and marginal employment in the calendar data. Since in the years from 2004 on, we observe more mothers in marginal than in part-time employment, we assume that before that year, all mothers who are working less than full-time are in marginal employment.
} 
gross earnings of the wife and further non labor income, such as rental and capital income 14 The income tax is computed by applying the income tax function to the taxable income of the household. Income tax and employee's social security contributions are deducted from gross income, and social transfers that depend on the employment state are added to derive net household income. Social transfers include child benefits, child-rearing benefits, unemployment compensation, housing benefits and social assistance. Finally, we subtract the household specific child care costs for households in which both spouses work.

\section{Gross hourly wages}

The employment state specific gross labor earnings of the wife are calculated on basis of the alternative specific working hours and a constant hourly gross wage. Therefore, it is necessary to derive the gross wage distribution for the working and non-working populations. This is the distribution of the offered marked wages which measures the signaled productivity of the women. For the working women in period $t$, we define their observed wage as their individual draw from the offered wage distribution.

For women belonging to the non-working population in period $t$ the draw from the offered wage distribution can not be observed. Therefore, it is necessary to estimate their expected gross hourly wages that is, the person specific distribution of offered wages $W_{i t}$. As $W_{i t}$ is not observable, we estimate $\hat{W}_{i t}$, a measure of the mean of the distribution of offered wages. More precisely, we estimate a Mincer wage equation with selection effects using the information of the working population and interpret the predicted hourly wages of the non-working individuals as the mean of the distribution of offered wages. The wage estimation is performed separately for East and West Germany. The specification and the estimation results are presented in more detail in the Appendix II.

\section{Socio-demographic variables}

In the empirical analysis we condition the joint employment and fertility decision in addition to the net household income on the standard socio-demographic variables. In particular, we allow fertility and the female employment behavior to depend on the age of both spouses, years of her formal education, the total number of children younger 18 years in the household, number of children younger than school age, region and nationality.

\subsection{Descriptive evidence}

In Figure 3 we show the average employment and fertility rate of women by age and by region. Female employment behavior in the states of the former socialist regions, i.e. East Germany, is still quite different from the behavior of women living in the western part. Although labor demand restrictions are higher in the East, employment rates of East German women are in general markedly higher. However, despite the different level of employment in both regions we find a similar shape of the employment rates by age which are increasing in the West from about

\footnotetext{
${ }^{14}$ For the sample of married households, labor income is by far the largest component of the gross household income. Non-labor income is assumed to be exogenous.
} 
about $50 \%$ at the age of 25 to close $78 \%$ at the last observed age. In the East the rates increase from about $60 \%$ to more than $85 \%$ over the same age.

\section{[Figure: 3: about here]}

Fertility rates in our sample are fairly similar between West and East Germany. Over all ages, we observe on average $8.3 \%$ of west German women with a newborn child and $7.5 \%$ in the East. Broken down by age we find the same pattern for both regions. Fertility rates are highest for women in their mid twenties and are declining with age. Hence, this trend is contrary to the increase in the employment rate by age.

In Tables 2 and 3 we show the employment behavior unconditional and conditional on fertility and by demographic characteristics.

\section{[Table 2 : about here]}

As expected, employment and fertility rates vary by demographic characteristics. In addition to the above discussed differences between East and West Germany, there are striking difference by education and family composition. Overall employment rates increase with education, and fertility rates are slightly higher for women with high education. The latter fact is certainly influenced by our sample selection. Since we condition our sample on married women older than 22 years, we do not observe the very young women who give birth and these tend to be women with lower education. Hence, caution is required when analyzing the empirical results by education in particular when focussing at the low education. Not surprisingly women without any other children have higher employment rates and a higher probability of having a newborn.

\section{[Table 3 : about here]}

Conditional on having a newborn, we observe as well strong differences in the employment behavior between the subgroups (Table 3). Interestingly, the group differences are fairly constant independent of the fertility status. The overall non-employment rate for women without a newborn is close to $25 \%$ whereas for mothers with a newborn it amounts to over $75 \%$. In contrast, the share of marginal employment increases with a newborn. This could be due to persistence in the employment behavior of women or driven by women changing from full-time work to marginal employment after giving birth. Further, we find interesting differences by the demographic subpopulations. As shown in Figure 3 employment rates in the East are higher than in the West. This finding changes with the fertility status. With a newborn, East German mothers are still more likely to have a regular job, however marginal employment is more common in the West. The data show a clear pattern by education. The highly educated, i.e. women with more than 13 years of formal schooling have the highest participation rates independent of their fertility status. On the contrary we find a strikingly low share of low educated women with less than 11 years of schooling in employment. In our sample only slightly more than $1 \%$ of the low educated with a newborn have a regular employment. Finally, we find an important difference in the employment behavior between women with and without other children. Women without 
other children who do not experience a birth have employment rates close to $90 \%$. Further, there is a difference in the employment behavior by the rank of the newborn. If the newborn is the first child employment rates of the mother are clearly higher than for women who have already at least one child.

\section{Estimation results}

In Table 4 we present the estimation results of the above specified joint model of fertility and female employment. In addition to the specification which accounts nonparametrically for unobserved individual effects, the Table includes as well a specification without unobserved heterogeneity. In general the coefficients of the two specifications are of similar magnitude, however according to the Akaike Criterion, which is based on the difference between the log likelihoods, the specifications are different. The significance of the discrete mass points and their related probabilities underline the importance of accounting for unobserved effects.

\section{[Table 4: about here]}

In general a separate interpretation of the size of the estimated coefficients is not meaningful. First, in non-linear discrete models marginal effects, or elasticities should be considered, second multiple interactions further complicate the interpretation of a single effect, and finally, as discussed in detail by Wooldridge (2005), when modelling the distribution of the random effects a clear interpretation of the time constant variables is not possible. Therefore, in the following section, we will derive group specific changes in the employment and fertility behavior induced by financial incentives which provide a better understanding how the female behavior varies by observable characteristics. However, some findings are worth mentioning.

Most important work incentives matter. We find a significant effect of the net household income on the employment and fertility choice. The majority of women has a positive preference for leisure time however this strongly varies by observed and unobserved characteristics. As discussed above a clear structural interpretation of fertility is very difficult, since in our specification preferences for children can not be separated from additional monetary and non-monetary costs. In line with previous studies, e.g. Hyslop (1999) we find significant evidence for state dependence in employment. Ceteris paribus the lagged leisure time significantly increases the preferences for leisure in the current period. As expected this effect is reduced once controlling for unobserved heterogeneity. On the contrary we find the expected negative effect of a birth in the last year on fertility in the current year. As mentioned above we find significant effects of unobserved heterogeneity. The correlation coefficients imply that there is positive correlation in the unobservables affecting the preferences for income and leisure while unobservables affecting the fertility decision are negatively correlated with those affecting leisure and income.

\section{Fit of the model}

Before discussing in detail the effect of financial incentives on fertility and female employment behavior, it is necessary to asses the quality of the empirical specification. In Figure 4 we present 
the simulated employment and fertility rates by age in comparison to the observed rates in the data. The simulation is based on the estimated coefficients of the observed and the unobserved characteristics ${ }^{15}$ The simulation shows that our model specification fits the observed age specific pattern very closely both in terms employment and fertility.

\section{[Figure 4 : about here]}

In Appendix III we present further specification checks, not only differentiated by age but also by region and education. In general the model replicates the data very precisely, although for sub populations with only few observations the model has problems to predict the exact age pattern.

\section{The effect of employment related financial incentives on employment and fer- tility}

In order to study how employment related financial incentives affect the female labor supply and fertility behavior, we simulate behavioral changes based on the estimated model for several subgroups. More precisely we analyze the labor supply and fertility responses of a $1 \%$ increase in the net income at work (Table 5). The effects should be interpreted as the short run or one period effects as we condition the behavioral changes on the observed behavior in the lagged period. To study the significance of the behavioral effects we derive a distribution of average effects based on a parametric bootstrap and present here the median and in italic the $5 \%$ and $95 \%$ confidence interval.

\section{[Table 5: about here]}

In general, we find that the female employment behavior reacts to financial incentives. Overall, as a result of the income increase for working women the total employment rate increases by about $0.7 \%$ and the average weekly working hours increase by $0.46 \%$. The lower increase in working hours implies that the additional financial incentives make marginal employment relatively more attractive than regular employment. Our results show the expected pattern of heterogeneity in the employment behavior which is in line with the above discussed difference in the employment behavior. While groups with a relatively strong labor market attachment, i.e. women in East Germany, highly educated women and women without children, only slightly change their employment behavior, the response of the other groups, in particular the low educated women, is markedly higher. According to our estimation fertility hardly reacts to the higher financial incentives for working women. On average we find a significant reduction by of about $0.5 \%$ in the fertility rate. This negative effect implies that the substitution effect dominates the income effect in the sense that the opportunity costs for children increase.

\section{The effect of child related financial incentives on employment and fertility}

Before evaluating the employment and fertility effects of a specific child care reform, we briefly discuss how women would react to an increase in overall child benefits. We calibrate this

\footnotetext{
${ }^{15}$ We use calibration methods (Empirical Bayes) to calculate for each household posterior probabilities of the discrete mass points, for details see e.g. Skrondal and Rabe-Hesketh (2004).
} 
hypothetical reform such that the fiscal costs before behavioral adjustment match those of the child care reform discussed in the next section. More precisely, child benefits for all children younger than three years are increased by 360 Euro per year which amounts to a $20 \%$ increase of the current child benefits. The purpose of the following analysis is twofold. First we want to show how women in general react to child related financial incentives such that we can compare our results to the previous literature. Second, we will use the findings as a comparison to the behavioral results of the child care reform.

\section{[Table 6 : about here]}

As expected we find a small but significant negative employment effect of the increase in overall child benefits. This transfer is unconditional of work and reduces work incentives relative to non-work given a positive income effect. On the contrary we find a positive and significant fertility effect of this reform of about $4.6 \%$. By subgroups the effects are quite similar, yet there exist some differences which can be either related to different financial incentives induced by higher child benefits or to heterogeneity in behavior. Financial incentives are highest for women with low wages, i.e. the low educated and women in East Germany, and in line with that we find above average fertility effects for those groups. As discussed above women without children have a higher probability to give birth, therefore they react strongest to the additional financial incentives.

The magnitude of these fertility effects is similar to what other studies have found. Milligan (2005) finds for Canada an increase in the probability of having a child of $17 \%$ if child benefits increase by 1,000 Canadian Dollars per year. In a study on US data, Whittington, Alm, and Peters (1990) find an average increase of $11 \%$ in the birthrate resulting from the 1989 reform of the personal exemption for dependents in the income tax. This reform increased the tax value of the personal exemption by almost 100 Dollar per year. In contrast to our reform, which increases transfers only for three years, the personal exemption for dependents is granted as long as a child is filed as dependent, usually for a minimum of 18 years. A study evaluating a recent reform of parental leave benefits in Austria by Lalive and Zweimueller (2005) shows that an additional year of parental leave benefits (worth about 4,080 Euro per year, granted for 2.5 years) increases the probability that mothers who already have one child get another child by $15 \%$ within the first three years after the first birth.

\section{How can the policy affect fertility and employment behavior?}

In the following, we use the empirical framework developed in this paper to study how policy reforms might at the same time stimulate female employment behavior and fertility. In particular we focus on an increase in subsidized public child care facilities for children younger than three years. In line with a recently introduced reform in Germany which will be fully implemented by the year 2013, we simulate a policy scenario without rationing for subsidized child care. More precisely, this reform provides subsidized day care for all children under three years if 
both parents are working 16 Given the high costs of private child care, this reform increases disposable household income by several hundred Euro, in particular if the mother is working full time.

\section{[Table 7: about here]}

The results show that this child care reform leads to positive employment effects: Participation increases by $1.6 \%$ and working hours by $2.4 \%$. As far as fertility is concerned, we do not find a significant effect, at least not for the population average. However, if we look in more detail on results for subgroups, we find some interesting differences: While the employment effects are very similar across East and West Germany, across education groups as well as by child parity, there are significant differences with respect to the fertility effect. For two groups we find large positive fertility effects, namely for highly educated women (7\%) and for women who are at risk to getting their first child (9\%).

The differences between the subgroups are in line with the financial incentives induced by this reform: The income gain under this child care reform depends on (i) working hours, (ii) number of children under the age of three years, (iii) rationing of subsidized child care before the reform and (iv) the opportunity costs for work. Mothers who already have one or more children below the age of three years have strong incentives to start employment. Therefore, their probability for an additional child decreases. In contrast, women who are currently childless only profit from the reform in case they get a child, which is why we find such a large fertility effect for this group. Highly educated women have the highest opportunity costs of work. Therefore the joint employment and fertility with subsidized child care is most attractive for this group.

When we compare the results from this child care reform to an increase in unconditional child benefits such as shown in the section above, ${ }^{17}$ we find that neither policy reform can tackle the challenges in demographic changes by fostering employment and fertility at the same time, at least not for the whole population. Overall, higher lump-sum benefits lead to an increase in the fertility rate, however at the cost of lower employment levels. Increasing subsidies for child care conditional on employment significantly increases participation and working hours, yet on average does not affect fertility.

However, our results suggest that the child care reform would have a double positive effect for two important subgroups. First, the probability of entering motherhood for the first time increases without negative employment effects. This is in contrast to an increase in child benefits as employment rates would be reduced for women giving birth to the first child. Second we find that both employment and fertility of highly educated women would positively react to higher

\footnotetext{
${ }^{16}$ Since we are only modelling mothers' labor supply, we assume that in case that the mother is working, the family is eligible for subsidized child care.

${ }^{17}$ The two reforms are designed to have the same fiscal costs before behavioral adjustment. We calculate that before behavioral adjustment the child care reform will cost about 750 million Euro per year, since there are about 130,000 children under the age of three who have working mothers but are not enrolled in subsidized child care. This group will become eligible for subsidized child care after the reform. Assuming average costs of 7,000 Euro per child per year, and subtracting average parents' fees of 1,200 Euro per child per year, we get overall costs of about 750 million Euro per year. With this amount, unconditional cash benefits could be increased by 360 Euro per year for all children under three years, which we simulated in the section above.
} 
subsidies for child care. Again, child benefits would lead to a reduction in employment for this subgroup.

Finally, when comparing the two different reforms it is necessary to mention that although both reforms have the same fiscal costs before behavioral changes, the adjustment of employment and fertility decisions will lead the child care reform to be less expensive since more women work and the overall child benefit to be more expensive since women drop out of the labor force and reduce working hours.

\section{Conclusion}

In this paper we have developed an intertemporal model of the joint decision of female employment and fertility. For the identification we exploit variation in the tax and transfer system which differs by employment and number of children. Additional variation comes from differences in child care costs that vary by working hours, household income and region. We allow for intertemporal feedback effects between employment and fertility by estimating a dynamic panel data model with random effects based on data from the German Socio Economic Panel (SOEP). Estimation results show that financial incentives do matter with respect to both decisions: We find a significant positive effect of net household income on employment and fertility. Moreover, we find state dependence in employment and - as expected - a negative effect of a birth in the last year on fertility in the current year. On top of that, we find significant effects of unobserved heterogeneity.

The second contribution of our paper is that we use the model to evaluate employment and fertility effects of policy reforms targeted to cope with the challenges of the demographic change. In particular, we are interested in analyzing whether a reform of child care subsidies for working mothers can meet two challenges at the same time, namely increasing employment and fertility. The hypothetical reform we evaluate is similar to a reform which will be implemented until the year 2013 in Germany. In particular it is the aim to provide all working women subsidized child care for their children younger three years. Our results show that this reform has significantly positive employment effects. On average, participation rates increase by $1.6 \%$ and working hours increase by $2.4 \%$. However, on average we do not find significant effect on fertility. Only for two important subgroups, namely highly educated women and women who give birth for the first time an increase in subsidized child care would lead to positive employment and fertility effects. Comparing the results of this particular child care reform to an increase in unconditional child benefits, we find that in the latter case there is a significant positive effect on fertility for all groups of women, yet at the cost of negative employment effects.

We thus conclude that for a country like Germany that has to deal with low fertility rates as well as low employment rates of mothers, it is very difficult to design family policy reforms that will tackle both demographic problems at the same time. However, providing conditional child care subsidies for working mothers seems to be more promising since i) for two subgroups we find a double positive effects and ii) the positive employment effect would significantly reduce the fiscal costs of this reform. 


\section{References}

AkAY, A. (2009): "The Wooldridge Method for the Initial Values Problem Is Simple: What About Performance?," IZA Discussion Paper, 3943.

Azmat, G., and L. Gonzalez (2009): "Targeting Fertility and Female Part icipation Through Income Tax," IZA Discussion Paper, 4405.

Baughman, R., and S. Dickert-Conlin (2003): "Did Expanding the EITC Promote Motherhood?," The American Economic Review, 93(2), 247-251.

Blank, R. (2002): "Evaluating Welfare Reform in the United States," Journal of Economic Literature, 40(4), 1105-1166.

Blau, D. M., and P. K. Robins (1989): "Fertility, Employment and Child-Care Costs," Demography, 26(2), 287-299.

Blundell, R. (2000): "Work Incentives and "In-work" Benefit Reforms: A Review," Oxford Review of Economic Policy, 16(1), 27-44.

Brewer, M., A. Ratcliffe, and S. Smith (2008): "Does welfare reform affect fertility? Evidence from the UK," IFS Working Paper, (9).

Carrasco, R. (2001): "Binary Choice Models With Binary Endogenous Regressors in Panel Data: Estimating the Effect of Fertility in Female Labor Participation," Journal of Business and Economics Statistics, 19, 385-394.

Del Boca, D., and R. Sauer (2009): "Life Cycle Employment and Fertility Across Institutional Environments," European Economic Review, 53(3), 274-292.

Francesconi, M. (2002): "A Joint Dynamic Model of Fertility and Work of Married Women," Journal of Labor Economics, 20(2), 336-380.

Gauthier, A. (2007): "The impact of family policies on fertility in industrialized countries: a review of the literature," Population Research and Policy Review, 26, 323-346.

HaAn, P., and K. Wrohlich (2009): "Optimal taxation: The design of child-related cash and in-kind benefits," German Economic Review, p. forthcoming.

Haisken De-New, J., and J. Frick (2005): Desktop Compendium to The German SocioEconomic Panel Study (SOEP). DIW.

Hank, K., M. Kreyenfeld, and C. K. Spiess (2004): "Kinderbetreung und Fertilität in Deutschland," Zeitschrift für Soziologie, 34.

Heckman, J. J., and B. Singer (1984): "A Method for Minimizing the Impact of Distributional Assumptions in Econometric Models for Duration Data," Econometrica, 52(2), 271-320. 
Hotz, V. J., And J. K. Scholz (2003): "The Earned Income Tax Credit," in Means-Tested Transfer Programs in the United States, ed. by R. A. Moffitt, pp. 141-198. Chicago: University of Chicago Press.

Hyslop, D. (1999): "State Dependence, Serial Correlation and Heterogeneity in Intertemporal Labor Force Participation of Married Women," Econometrica, 67(6), 1255-1294.

Keane, M., and K. Wolpin (2002): "Estimating Welfare Effects Consistent with ForwardLooking Behavior: Part II: Empirical Results," Journal of Human Resources, 37, 600-622.

Lalive, R., and J. Zweimueller (2005): "Does Parental Leave Affect Fertility and Returnto-Work? Evidence from a "True Natural Experiment"," IZA Discussion Paper, (1613).

Laroque, G., and B. Salanie (2004): "Fertility and Financial Incentives in France," CESifo Economic Studies, 50, $423-450$.

- (2008): "Does Fertility Respond to Financial Incentives?," IZA Discussion Paper, 3575.

McFadden, D. (1974): Conditional Logit Analysis of Qualitative Choice Behaviorpp. 105-142. New York Academic Press.

Michaud, P., and K. Tatsiramos (2008): "Fertility and Female Employment Dynamics in Europe: The Effect of Using Alternative Econometric Modeling Assumptions," IZA DiscussionPaper, 3853.

Milligan, K. (2005): "Subsidizing the Storck: New Evidence on Tax Incentives and Fertility," The Review of Economics and Statistics, 87(3), 539-555.

Skrondal, A., and S. Rabe-Hesketh (2004): Generalized Latent Variable Modeling. Chapman and Hall.

Spiess, C., And K. Wrohlich (2008): "Parental Leave Reform in Germany: Costs and Labor Market Outcomes of Moving towards the Nordic Model," Population Research and Policy Review, 27(5), 575-5910.

Steiner, V., P. HaAn, and K. Wrohlich (2005): "Dokumentation des Steuer-TransferMikrosimulationsmodells 1999-2002," Data Documentation 9.

Steiner, V., And K. Wrohlich (2004): "Household Taxation, Income Splitting and Labor Supply Incentives. A Microsimulation Study for Germany," CESifo Economic Studies, 50, $541-568$.

Whittington, L. A., J. Alm, and H. E. Peters (1990): "Fertility and the Personal Exemption: Implicit Pronatalist Policy in the United States," The American Economic Review, $80(3), 545-556$.

Wooldridge, J. M. (2005): "Simple Solutions to the Initial Conditions Problem in Dynamic, Nonlinear Panel Data Models with Unobserved Heterogeneity," Journal of Applied Econometrics, 20(1), 39-54. 
Wrohlich, K. (2006): "Labor Supply and Child Care Choices in a Rationed Child Care Market," IZA Discussion-Paper, 2053.

Wrohlich, K. (2007): Evaluating Family Policy Reforms Using Behavioral Microsimulation. The Example of Childcare and Income Tax Reforms in Germany. PhD Thesis, Free University of Berlin.

Wrohlich, K. (2008): "The Excess Demand for Subsidized Child Care in Germany," Applied Economics, 40(10), 1217-1228. 


\section{Appendix I: Calculation of child care costs}

Following Wrohlich (2006) we argue that given the considerable excess demand for subsidized child care facilities in Germany, we have to calculate a measure of child care costs that takes rationing explicitly into account. In Germany, parents' fees to subsidized child care facilities are relatively low, however, access to these slots is rationed in many regions in Germany, in particular for children below the age of three years. Families who do not have access to subsidized child care have to rely on the private market of nannies or babysitters, which comes at considerably higher costs. Since we do not know in the data whether a family is restricted in the access to subsidized child care or not, we use a measure of "expected costs of child care" that consist of a weighted average of parents' fees to subsidized child care and costs of private child care. As weights we use the number of subsidized child care slots in a county (Kreis) per 100 children within each age group (0-3 years and 3-6 years). The costs of private child care $c^{n s}$, i.e. costs for a nanny or other forms of privately organized day care is set at 5 Euro per hour for the years 1999 to 2002 and 6 Euro for the years 2003 to 2006. The parents fees for subsidized child care are predicted for each child on the basis of estimations of parents' fees reported in the SOEP in the waves 2002, 2005 and 2007. Fees for part-time and full-time care are estimated separately using Tobit models. This method is chosen since about $10 \%$ of all parents do not have to pay at all for center-based child care. Estimation results are presented below.

[Table 8: about here]

\section{Appendix II: Wage estimation}

[Table 9]: about here]

\section{Appendix III: Model fit by region and education}

[Figures 5 and 6 : about here] 
Table 1: Variation in childcare costs across states (2006)

\begin{tabular}{l|cccc}
\hline \hline $\begin{array}{l}\text { Population Density } \\
\text { (number of inhabitants) }\end{array}$ & \multicolumn{2}{|c}{ East Germany } & \multicolumn{2}{c}{ West Germany } \\
\hline$<20.000$ & 90 & 307 & 100 & 447 \\
$20.000-<100.000$ & 88 & 267 & 100 & 433 \\
$100.000-<500.000$ & 92 & 299 & 101 & 446 \\
$>500.000$ & 103 & 362 & 105 & 406 \\
\hline \hline
\end{tabular}

Source: Own calculations based on SOEP and data on child care availability from the German statistical office.

Table 2: Employment and birth rate

\begin{tabular}{lcc}
\hline \hline & Employment Rate & Fertility Rate \\
\hline & & \\
East Germany & 78.46 & 7.49 \\
West Germany & 69.28 & 8.34 \\
Low Education & 54.73 & 7.91 \\
Medium Education & 73.63 & 7.94 \\
High Education & 80.23 & 9.67 \\
Other Children & 67.6 & 6.4 \\
No Other Children & 82.65 & 13.52 \\
All & & \\
\hline \hline
\end{tabular}

Low education: less than 11 years of formal schooling, medium education: between 11 and 13 years of formal schooling, high education: more than 13 years of formal schooling. Employment state of mothers of the newborn is observed 12 months after giving birth.

Source: SOEP, wave 2000-2007.

Table 3: Distribution of employment states

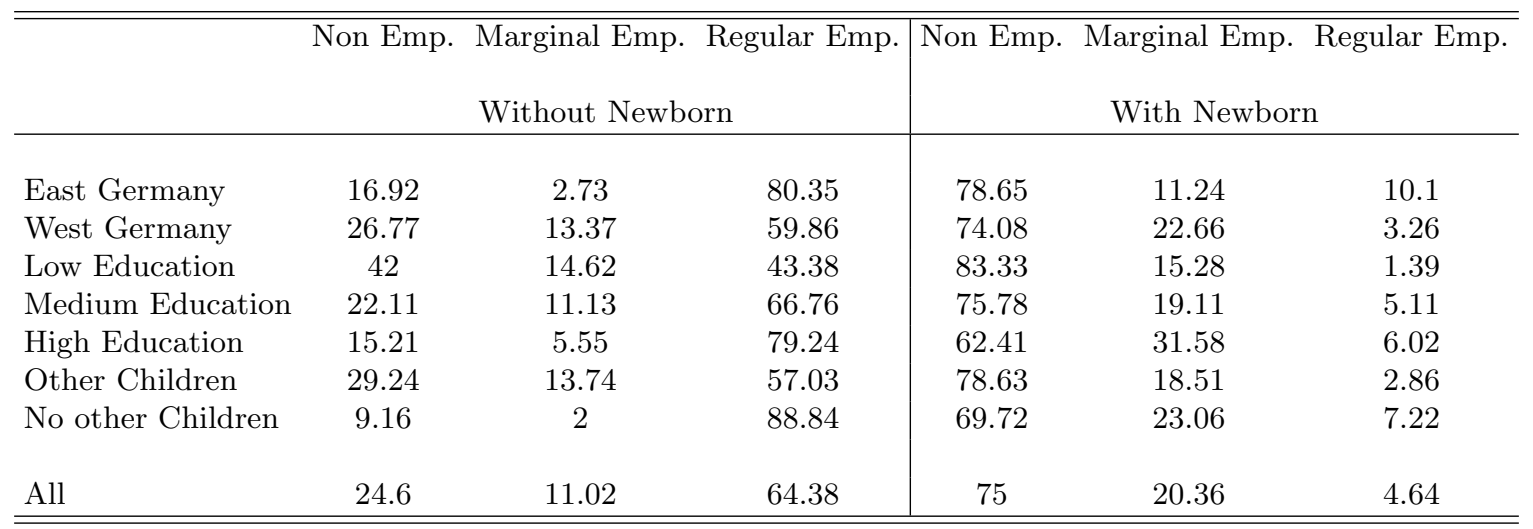

Low education: less than 11 years of formal schooling, medium education: between 11 and 13 years of formal schooling, high education: more than 13 years of formal schooling. Marginal employment includes part-time work. Employment state of mothers of the newborn is observed 12 months after giving birth.

Source: SOEP, wave 2000-2007. 
Table 4: Estimation results

\begin{tabular}{|c|c|c|c|c|c|c|}
\hline & \multicolumn{3}{|c|}{ Model without random effects } & \multicolumn{3}{|c|}{ 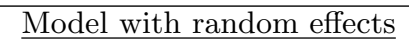 } \\
\hline & Coef. & Std. error & t-stats & Coef. & Std. error & t-stats \\
\hline Income & 10.140 & 1.412 & 7.181 & 9.536 & 1.714 & 5.563 \\
\hline Leisure & -9.927 & 0.472 & -21.022 & -7.079 & 0.548 & -12.928 \\
\hline Fertility & -15.856 & 0.521 & -30.423 & -19.167 & 0.793 & -24.176 \\
\hline Income* Number of Children & -0.373 & 0.175 & -2.129 & -0.660 & 0.209 & -3.156 \\
\hline Income* Wife younger 30 years & 0.972 & 0.687 & 1.415 & 0.240 & 0.835 & 0.288 \\
\hline Income* Wife aged between $30-34$ years & 0.996 & 0.492 & 2.027 & 0.800 & 0.623 & 1.284 \\
\hline Income* Wife aged between 35 - 39 years & 1.818 & 0.460 & 3.953 & 1.857 & 0.597 & 3.114 \\
\hline Income* Husband's age & -13.825 & 3.034 & -4.557 & -9.428 & 3.587 & -2.629 \\
\hline Income*Leisure & -0.165 & 0.032 & -5.099 & -0.188 & 0.045 & -4.177 \\
\hline Leisure $^{2}$ & 0.569 & 0.034 & 16.643 & 0.372 & 0.039 & 9.538 \\
\hline Leisure* Wife younger 30 years & -6.040 & 1.097 & -5.505 & -7.071 & 1.149 & -6.155 \\
\hline Leisure* Wife aged between $30-34$ years & -0.215 & 0.660 & -0.326 & -0.276 & 0.730 & -0.378 \\
\hline Leisure* Wife aged between 35 - 39 years & 0.056 & 0.659 & 0.086 & 0.304 & 0.728 & 0.417 \\
\hline Leisure $^{2 *}$ Wife younger 30 years & 0.455 & 0.085 & 5.373 & 0.525 & 0.089 & 5.918 \\
\hline Leisure $^{2 *}$ Wife aged between $30-34$ years & 0.016 & 0.051 & 0.320 & 0.015 & 0.057 & 0.267 \\
\hline Leisure $^{2 *}$ Wife aged between $35-39$ years & 0.001 & 0.051 & 0.020 & -0.022 & 0.057 & -0.377 \\
\hline Leisure* Husband's age & -1.458 & 0.347 & -4.204 & -1.346 & 0.403 & -3.338 \\
\hline Leisure* Birth in last period & -0.245 & 0.031 & -7.964 & -0.021 & 0.041 & -0.496 \\
\hline Leisure* Number of Children & 0.033 & 0.017 & 1.879 & 0.069 & 0.023 & 2.970 \\
\hline Leisure* German & -0.038 & 0.033 & -1.162 & -0.044 & 0.046 & -0.946 \\
\hline Leisure* East Germany & -0.209 & 0.029 & -7.340 & -0.244 & 0.039 & -6.327 \\
\hline Leisure* Low education & 0.078 & 0.044 & 1.788 & 0.208 & 0.059 & 3.502 \\
\hline Leisure* Medium education & -0.043 & 0.036 & -1.201 & -0.044 & 0.048 & -0.923 \\
\hline Leisure* Married & -0.055 & 0.040 & -1.370 & -0.070 & 0.055 & -1.281 \\
\hline Leisure* Lagged leisure & 3.954 & 0.088 & 45.089 & 3.079 & 0.113 & 27.220 \\
\hline Leisure* Initial leisure & 1.159 & 0.088 & 13.154 & 1.647 & 0.124 & 13.304 \\
\hline Leisure* Fertility & 1.041 & 0.067 & 15.439 & 1.420 & 0.093 & 15.314 \\
\hline Fertility* Income & 3.063 & 0.134 & 22.807 & 3.493 & 0.178 & 19.637 \\
\hline Fertility* Number of Children & -1.211 & 0.103 & -11.722 & -1.151 & 0.120 & -9.599 \\
\hline Fertility* Birth in last period & -0.896 & 0.135 & -6.621 & -1.448 & 0.155 & -9.325 \\
\hline Fertility* Wife younger 30 years & 2.656 & 0.217 & 12.218 & 2.387 & 0.261 & 9.132 \\
\hline Fertility* Wife aged between $30-34$ years & 2.337 & 0.166 & 14.055 & 2.132 & 0.200 & 10.642 \\
\hline Fertility* Wife aged between $35-39$ years & 1.375 & 0.162 & 8.485 & 1.025 & 0.189 & 5.412 \\
\hline Fertility* German & 0.208 & 0.132 & 1.573 & 0.123 & 0.153 & 0.804 \\
\hline Fertility* East Germany & 0.465 & 0.139 & 3.349 & 0.263 & 0.162 & 1.623 \\
\hline Fertility* Low education & -0.546 & 0.167 & -3.266 & -0.820 & 0.193 & -4.240 \\
\hline Fertility* Medium education & -0.228 & 0.124 & -1.841 & -0.052 & 0.146 & -0.352 \\
\hline Fertility* Married & 0.544 & 0.173 & 3.145 & 0.213 & 0.199 & 1.070 \\
\hline Fertility* Lagged leisure & 5.341 & 0.569 & 9.384 & 6.598 & 0.656 & 10.055 \\
\hline Fertility* Initial leisure & -2.916 & 0.404 & -7.211 & -3.656 & 0.464 & -7.874 \\
\hline Fertility* Initial fertility & -0.006 & 0.094 & -0.068 & -0.130 & 0.105 & -1.237 \\
\hline Income* Mass Point 1 & & & & 1.421 & 1.956 & 0.727 \\
\hline Income* Mass Point 2 & & & & 3.656 & 0.982 & 3.722 \\
\hline Leisure* Mass Point 1 & & & & 9.851 & 3.356 & 2.935 \\
\hline Leisure* Mass Point 2 & & & & -0.943 & 0.073 & -12.864 \\
\hline Fertility* Mass Point 1 & & & & -2.206 & 0.352 & -6.265 \\
\hline Fertility* Mass Point 2 & & & & 2.068 & 0.291 & 7.115 \\
\hline$\pi_{1}$ & & & & -1.212 & 0.135 & -9.007 \\
\hline$\pi_{2}$ & & & & -2.577 & 0.121 & -21.346 \\
\hline Correlation (Income, Leisure) & & & & 0.735 & 0.245 & \\
\hline Correlation (Income, Fertility) & & & & -0.433 & 0.302 & \\
\hline Correlation (Fertility, Leisure) & & & & -0.915 & 0.030 & \\
\hline Log likelihood & 7544.620 & & & 7330.990 & & \\
\hline
\end{tabular}

Number of observations: 10845. Low education: less than 11 years of formal schooling, medium education: between 11 and 13 years of formal schooling, high education: more than 13 years of formal schooling. In parenthesis we present the group specific employment. and birth rates. $\pi_{1}$ and $\pi_{2}$ are transformed probabilities. Standard errors of the correlations are derived using parametric bootstrap with 1000 replications.

Source: SOEP, wave 2000-2007, STSM. 
Table 5: Average behavioral effects of an increase in income at work in \%

\begin{tabular}{lccccccccc}
\hline \hline & \multicolumn{3}{c}{ Change in Employment } & \multicolumn{2}{c}{ Change in Working Hours } & \multicolumn{2}{c}{ Change in Fertility } \\
& 5th Perc. Median & 95th Perc. & 5th Perc. Median & 95th Perc. & 5th Perc. Median & 95 th Perc. \\
\hline \multirow{2}{*}{ East Germany } & 0.41 & 0.44 & 0.47 & 0.27 & 0.29 & 0.31 & -0.70 & -0.57 & -0.41 \\
West Germany & 0.73 & 0.81 & 0.87 & 0.47 & 0.52 & 0.56 & -0.56 & -0.46 & -0.32 \\
Low Education & 1.05 & 1.16 & 1.26 & 0.67 & 0.73 & 0.79 & -0.64 & -0.55 & -0.45 \\
Medium Education & 0.61 & 0.68 & 0.72 & 0.40 & 0.44 & 0.47 & -0.60 & -0.50 & -0.37 \\
High Education & 0.46 & 0.52 & 0.55 & 0.28 & 0.32 & 0.35 & -0.44 & -0.31 & -0.13 \\
Other children & 0.75 & 0.83 & 0.90 & 0.51 & 0.57 & 0.60 & -0.78 & -0.65 & -0.49 \\
No children & 0.40 & 0.43 & 0.47 & 0.21 & 0.23 & 0.26 & -0.35 & -0.23 & -0.11 \\
All & 0.65 & 0.72 & 0.77 & 0.42 & 0.46 & 0.49 & -0.58 & -0.48 & -0.35 \\
\hline \hline
\end{tabular}

Low education: less than 11 years of formal schooling, medium education: between 11 and 13 years of formal schooling, high education: more than 13 years of formal schooling. Confidence intervals are derived using parametric bootstrap with 100 replications.

Source: SOEP, wave 2000-2007, STSM.

Table 6: Average behavioral effects of an increase in child care benefits in \%

\begin{tabular}{|c|c|c|c|c|c|c|c|c|c|}
\hline & \multicolumn{3}{|c|}{ Change in Employment } & \multicolumn{3}{|c|}{ Change in Working Hours } & \multicolumn{3}{|c|}{ Change in Fertility } \\
\hline & 5th Perc. & Median & 95th Perc. & 5th Perc. & Median & 95th Perc. & 5th Perc. & Median & 95th Perc. \\
\hline East Germany & -0.14 & -0.12 & -0.10 & -0.22 & -0.19 & -0.17 & 4.63 & 5.04 & 5.42 \\
\hline West Germany & -0.14 & -0.13 & -0.11 & -0.23 & -0.21 & -0.19 & 4.24 & 4.50 & 4.79 \\
\hline Low Education & -0.17 & -0.15 & -0.13 & -0.27 & -0.24 & -0.21 & 4.95 & 5.27 & 5.59 \\
\hline Medium Education & -0.14 & -0.13 & -0.11 & -0.22 & -0.20 & -0.18 & 4.25 & 4.55 & 4.80 \\
\hline High Education & -0.12 & -0.11 & -0.09 & -0.24 & -0.21 & -0.19 & 3.89 & 4.22 & 4.53 \\
\hline Other children & -0.14 & -0.13 & -0.12 & -0.21 & -0.19 & -0.18 & 4.99 & 5.29 & 5.60 \\
\hline No children & -0.14 & -0.12 & -0.11 & -0.27 & -0.24 & -0.21 & 3.29 & 3.63 & 3.90 \\
\hline All & -0.14 & -0.13 & -0.11 & -0.23 & -0.21 & -0.19 & 4.32 & 4.62 & 4.88 \\
\hline
\end{tabular}

Low education: less than 11 years of formal schooling, medium education: between 11 and 13 years of formal schooling, high education: more than 13 years of formal schooling. Confidence intervals are derived using parametric bootstrap with 100 replications.

Source: SOEP, wave 2000-2007, STSM. 
Table 7: Average behavioral effects of an increase in child care subsidies in \%

\begin{tabular}{lccccccccc}
\hline \hline & \multicolumn{3}{c}{ Change in Employment } & \multicolumn{2}{c}{ Change in Working Hours } & \multicolumn{3}{c}{ Change in Fertility } \\
& 5th Perc. Median & 95th Perc. & 5th Perc. & Median & 95th Perc. & 5th Perc. Median & 95 th Perc. \\
\hline & & & & & & & & \\
East Germany & 1.31 & 1.40 & 1.48 & 1.79 & 1.93 & 2.06 & -5.08 & -2.28 & 1.25 \\
West Germany & 1.58 & 1.69 & 1.78 & 2.40 & 2.58 & 2.73 & -1.46 & 0.34 & 2.87 \\
Low Education & 1.84 & 1.98 & 2.15 & 2.70 & 2.96 & 3.23 & -4.32 & -3.18 & -2.07 \\
Medium Education & 1.51 & 1.62 & 1.71 & 2.24 & 2.41 & 2.54 & -2.84 & -0.95 & 1.89 \\
High Education & 1.17 & 1.26 & 1.34 & 1.78 & 1.91 & 2.06 & 4.00 & 6.73 & 10.59 \\
Other children & 1.63 & 1.74 & 1.84 & 2.49 & 2.67 & 2.82 & -7.65 & -6.31 & -4.74 \\
No children & 1.20 & 1.29 & 1.42 & 1.66 & 1.79 & 1.98 & 5.89 & 8.80 & 13.04 \\
& & & & & & & & & \\
All & 1.51 & 1.62 & 1.71 & 2.24 & 2.41 & 2.55 & -1.87 & -0.18 & 2.46 \\
\hline \hline
\end{tabular}

Low education: less than 11 years of formal schooling, medium education: between 11 and 13 years of formal schooling, high education: more than 13 years of formal schooling. In parenthesis we present the group specific employment and birth rates. Confidence intervals are derived using parametric bootstrap with 100 replications.

Source: SOEP, wave 2000-2007, STSM.

Table 8: Estimation of parents' fees for center-based childcare

\begin{tabular}{|c|c|c|c|c|}
\hline & \multicolumn{2}{|c|}{ Part-time care } & \multicolumn{2}{|c|}{ Full-time care } \\
\hline & Coeff. & St. Err. & Coeff. & St. Err \\
\hline Dummy variable indicating that child is aged $0-3$ & 17.86 & 6.22 & 33.35 & 10.09 \\
\hline Number of children in household & -11.68 & 2.14 & -21.18 & 5.23 \\
\hline Number of siblings in childcare & -17.18 & 3.31 & -19.59 & 8.10 \\
\hline Gross monthly income of parents/1000 & 0.58 & 0.05 & 0.68 & 0.14 \\
\hline Schlewig-Holstein & 22.06 & 8.63 & 115.97 & 35.89 \\
\hline Hamburg & 59.62 & 17.05 & 16.310 & 28.27 \\
\hline Niedersachsen & 27.16 & 5.09 & 18.84 & 20.52 \\
\hline Bremen & 20.52 & 15.2 & 115.83 & 49.70 \\
\hline Hessen & 19.31 & 5.87 & 11.59 & 16.67 \\
\hline Rheinland-Pfalz & -13.75 & 5.87 & -54.12 & 16.06 \\
\hline Baden-Wuerttemberg & -4.87 & 4.62 & -50.59 & 13.98 \\
\hline Bayern & 1.32 & 4.52 & -3.46 & 14.25 \\
\hline Mecklenburg-Vorpommern & 40.17 & 18.39 & 1.86 & 19.66 \\
\hline Brandenburg & -3.35 & 12.77 & -47.12 & 15.56 \\
\hline Sachsen-Anhalt & 15.17 & 10.10 & -3.36 & 15.88 \\
\hline Thueringen & 31.29 & 13.09 & -44.24 & 13.02 \\
\hline Sachsen & 2.65 & 8.19 & -39.20 & 12.25 \\
\hline Berlin & -1.88 & 12.84 & -21.52 & 16.97 \\
\hline Year 2005 & 5.20 & 3.39 & 14.06 & 8.50 \\
\hline Year 2007 & 8.44 & 3.57 & -0.70 & 8.57 \\
\hline Intercept & 59.97 & 5.95 & 133.13 & 15.08 \\
\hline$\sigma$ & 47.14 & 1.08 & 68.84 & 2.47 \\
\hline Log-Likelihood & -5440.2862 & & -2310.5862 & \\
\hline Number of observations & & 1128 & & 438 \\
\hline Thereof: Left-censored & & 123 & & 36 \\
\hline
\end{tabular}

Source: Estimations based on SOEP, wave 2002, 2005 and 2007. 
Table 9: Wage estimation

\begin{tabular}{|c|c|c|c|c|}
\hline & \multicolumn{2}{|c|}{$\underline{\text { East Germany }}$} & \multicolumn{2}{|c|}{ West Germany } \\
\hline & Coeff. & St. Err. & Coeff. & St. Err. \\
\hline \multicolumn{5}{|c|}{ Wage Equation } \\
\hline Years of Education & 0.059 & 0.003 & 0.066 & 0.003 \\
\hline Years of Full Time Work & 0.016 & 0.004 & 0.032 & 0.005 \\
\hline Years of Full Time Work ${ }^{2}$ & -0.033 & 0.013 & -0.098 & 0.025 \\
\hline Years of Part Time Work & 0.006 & 0.004 & 0.015 & 0.006 \\
\hline Years of Part Time Work ${ }^{2}$ & -0.006 & 0.028 & -0.053 & 0.044 \\
\hline Tenure & 0.024 & 0.003 & 0.023 & 0.006 \\
\hline Tenure $^{2}$ & -0.051 & 0.012 & -0.049 & 0.026 \\
\hline Loss of human capital & -0.056 & 0.009 & -0.039 & 0.009 \\
\hline Years of Education x German & & & 0.005 & 0.002 \\
\hline Years of Full Time Work x German & & & -0.001 & 0.005 \\
\hline Years of Full Time Work ${ }^{2} \mathrm{x}$ German & & & 0.011 & 0.026 \\
\hline Years of Part Time Work x German & & & -0.016 & 0.007 \\
\hline Years of Part Time Work ${ }^{2} \times$ German & & & 0.061 & 0.047 \\
\hline Tenure x German & & & 0.000 & 0.006 \\
\hline Tenure $^{2}$ x German & & & 0.000 & 0.027 \\
\hline Loss of human capital x German & & & 0.016 & 0.010 \\
\hline \multicolumn{5}{|c|}{ Selection Equation } \\
\hline Medium Education & 0.684 & 0.137 & 0.253 & 0.045 \\
\hline Higher Education & 1.347 & 0.122 & 0.519 & 0.038 \\
\hline Vocational Degree & 1.230 & 0.118 & 0.565 & 0.033 \\
\hline University Degree & 2.031 & 0.127 & 1.116 & 0.041 \\
\hline Years of Full Time Work & 0.114 & 0.009 & 0.140 & 0.005 \\
\hline Years of Full Time Work ${ }^{2}$ & -0.120 & 0.044 & -0.280 & 0.026 \\
\hline Years of Part Time Work & 0.137 & 0.015 & 0.156 & 0.007 \\
\hline Years of Part Time Work ${ }^{2}$ & -0.080 & 0.125 & -0.371 & 0.053 \\
\hline German & & & 0.008 & 0.031 \\
\hline Health 1 & -0.019 & 0.006 & -0.006 & 0.003 \\
\hline Health 2 & 0.007 & 0.007 & -0.009 & 0.004 \\
\hline Married & 0.312 & 0.043 & -0.134 & 0.024 \\
\hline Child younger 3 & -0.945 & 0.056 & -1.231 & 0.031 \\
\hline Child between 3 and 6 & -0.015 & 0.056 & -0.396 & 0.027 \\
\hline Child between 6 and 17 & -0.363 & 0.041 & -0.476 & 0.023 \\
\hline Total Number od Children & -0.343 & 0.044 & -0.064 & 0.025 \\
\hline Other Household Income & 0.000 & 0.000 & 0.000 & 0.000 \\
\hline Mills Ratio & 0.008 & 0.025 & 0.029 & 0.011 \\
\hline \multicolumn{5}{|l|}{ Number of observations } \\
\hline Censored & \multicolumn{2}{|c|}{3191} & \\
\hline Uncensored & \multicolumn{2}{|c|}{4079} & \multicolumn{2}{|c|}{12295} \\
\hline
\end{tabular}

Notes: Wages are gross hourly wages measured in logs. Loss of human capital is a weighted measure of years of unemployment capturing depreciation of human capital. Estimation is based on pooled data for the period 20002007. Time and region specific (Bundesland) dummies as well as dummies for industry sector and firms size and a constant term have been included in the estimation.

Source: SOEP, wave 2000-2007. 
Figure 1: Additional net household income in case of a newborn child by gross annual income

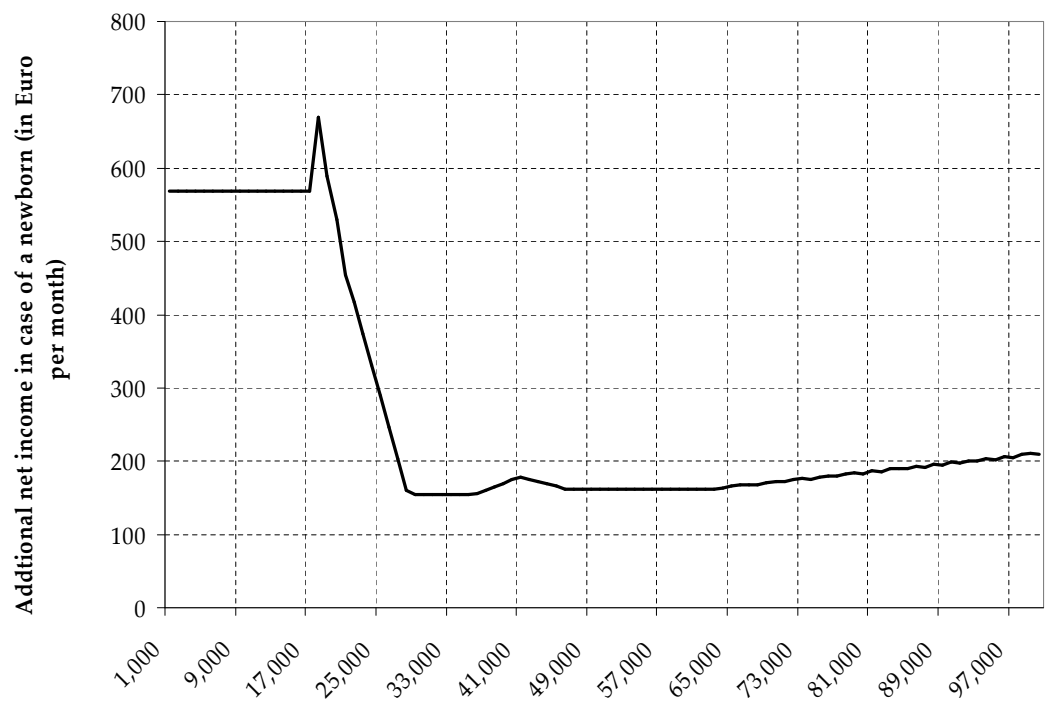

Gross household income (in Euro per year)

Source: Own calculations based on STSM.

Figure 2: Net household income by working hours of the mother

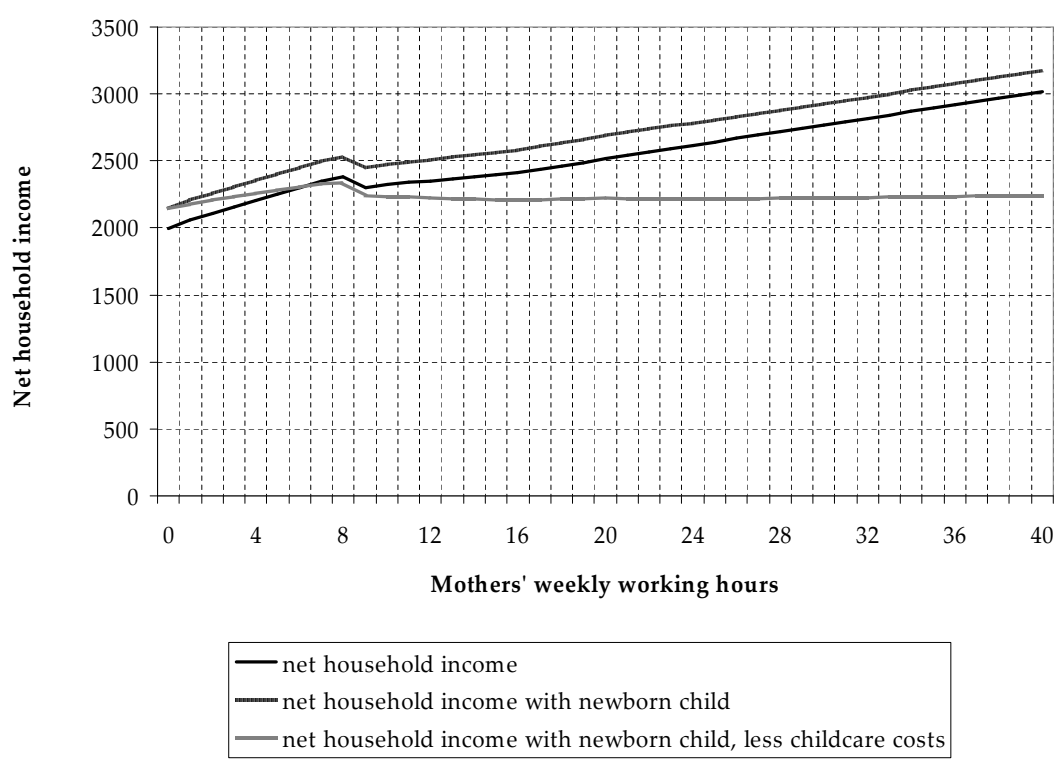

Source: Own calculations based on STSM. 
Figure 3: Observed employment and fertility by age

34 - Employment rates: West and East Germany

3 3 - Fertility rates: West and East Germany
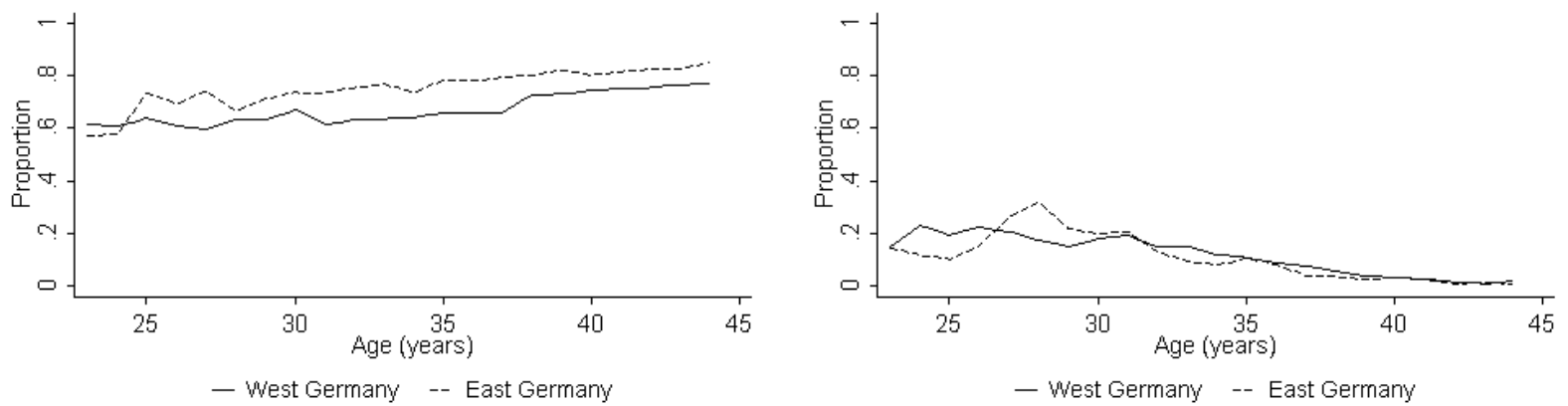

- West Germany -- East Germany

Source: SOEP 2000 - 2007.

Figure 4: Model fit by age

44 - Employment rates

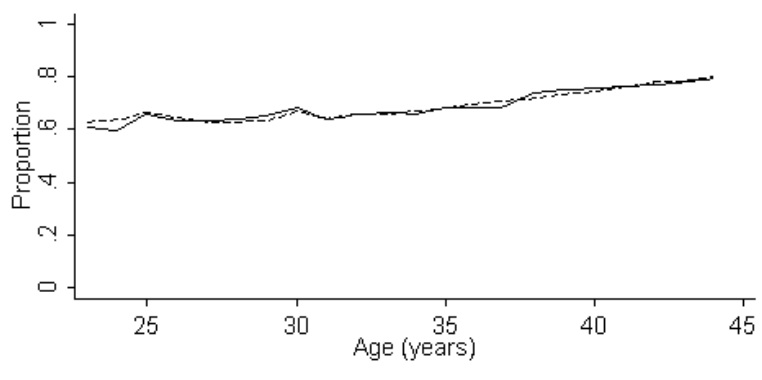

- Observed -- Simulated

Source: SOEP 2000 - 2007.
$4 \mathrm{~B}$ - Fertility rates

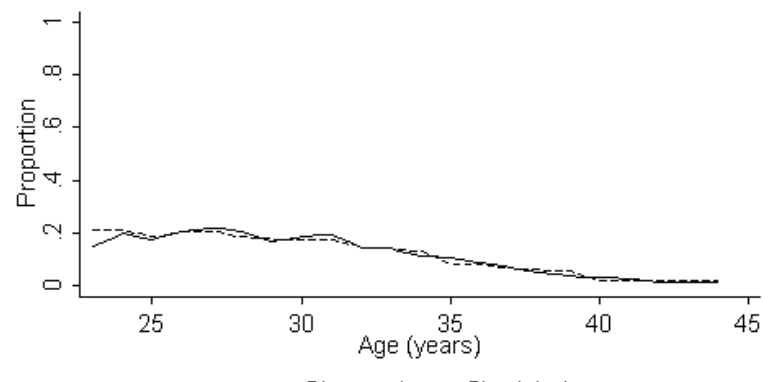

- Observed -- Simulated 
Figure 5: Model fit by age and region

5 A - Employment rates: West

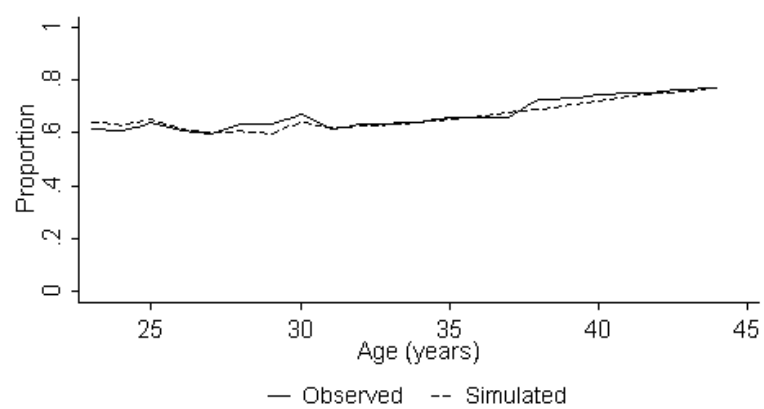

5 C - Employment rates: East

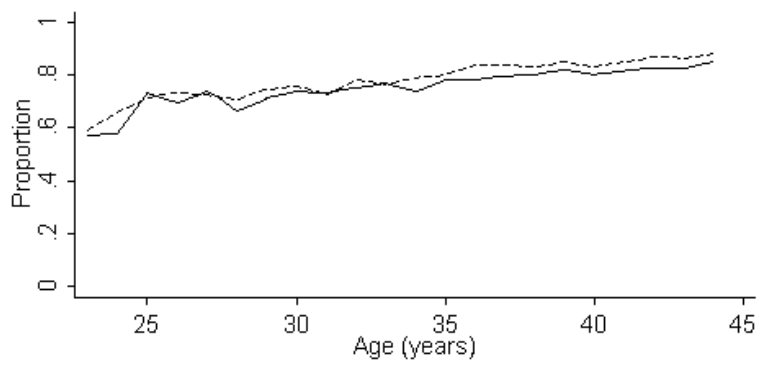

- Observed -- Simulated

Source: SOEP 2000 - 2007.
5 B - Fertility rates: West

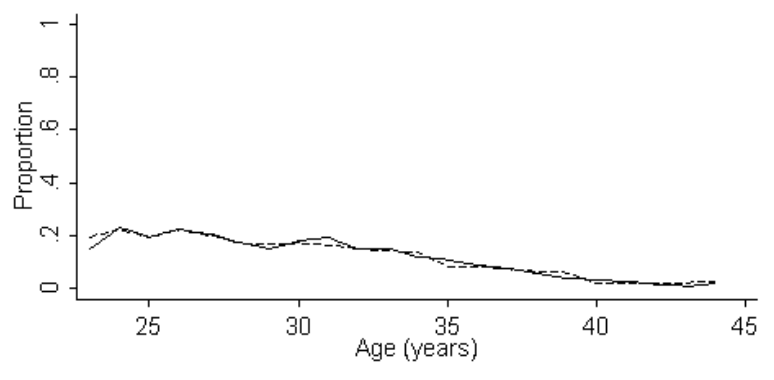

- Observed -- Simulated

5 D - Fertility rates: East

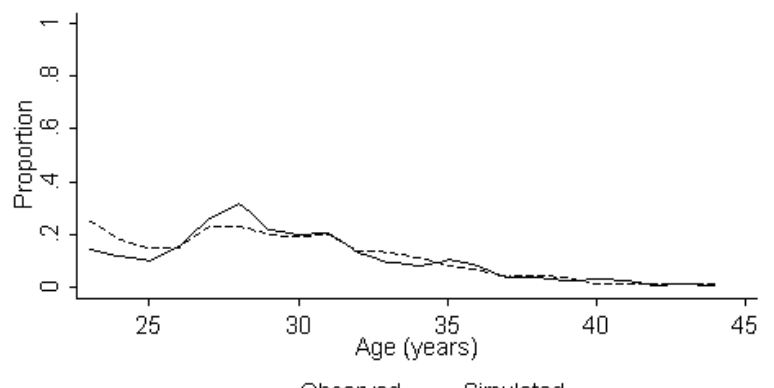

- Observed -- Simulated 
Figure 6: Model fit by age and education

64 - Employment rates: low education

$6 \mathrm{~B}$ - Fertility rates: low education
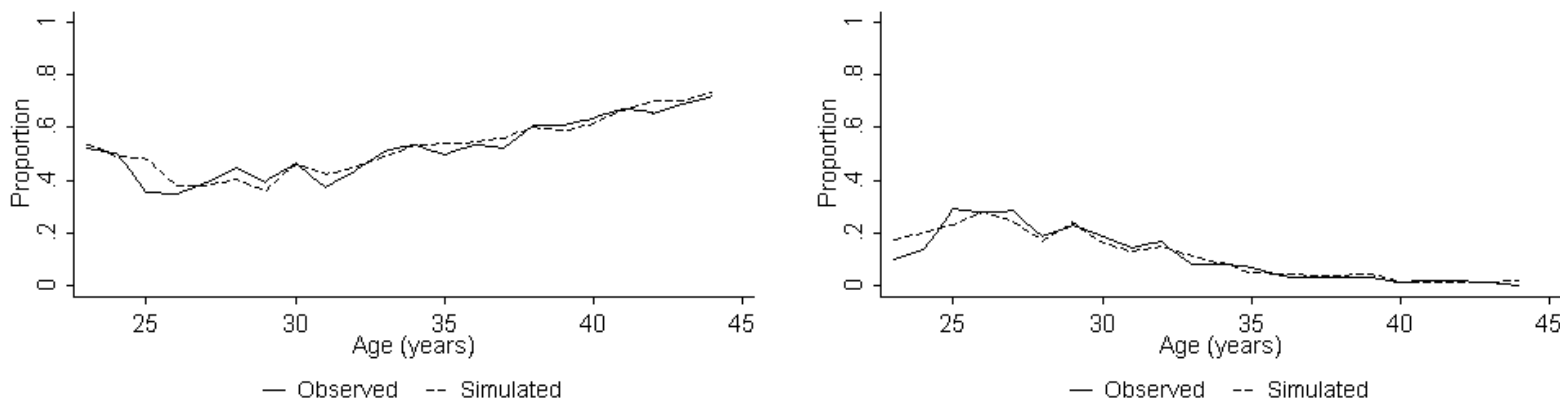

- Observed -- Simulated

6C - Employment rates: medium education

6D - Fertility rates: medium education
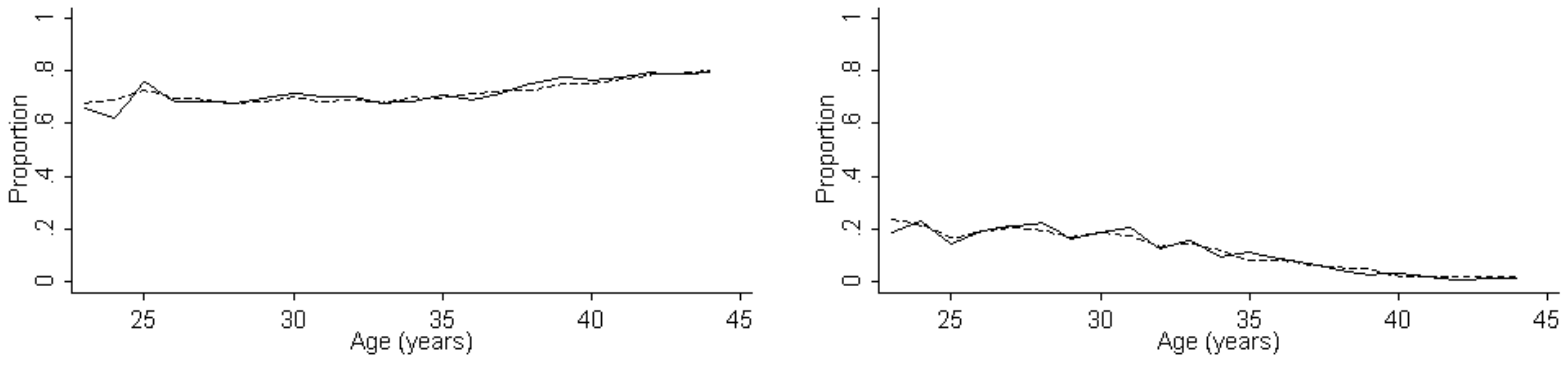

- Observed -- Simulated

- Observed -- Simulated

6 E - Employment rates: high education

6 F - Fertility rates: high education
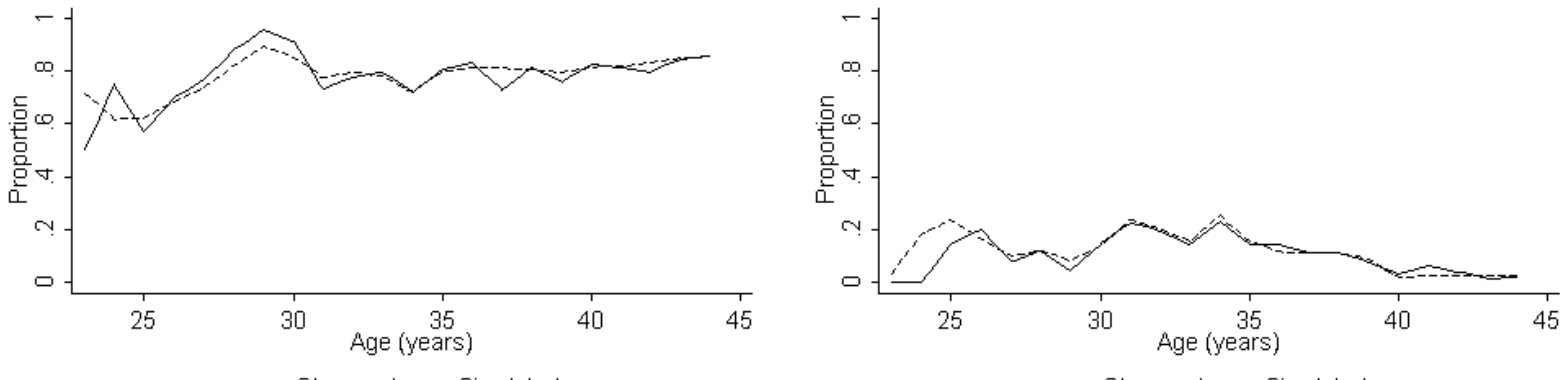

Source: SOEP 2000 - 2007. 